\title{
The Empirical Study on the Relationship between Knowledge Integration and IT Project Performance
}

\author{
Ying Cui ${ }^{\mathrm{a}, \mathrm{b}, *}$ \\ ${ }^{a}$ Hohai University, Nanjing, 210098, China \\ ${ }^{b}$ Henan University of Technology, Zhengzhou, 450001, China
}

\begin{abstract}
This article examines the relationship between timely project completion and the management's integrative capability. Measures of the integrative capability are used to predict on-time project completion, where completion is a function of the duration of IT-related project delays. In a longitudinal study of 74 enterprise application integration projects in the medical sector, integrative capability was measured from the point of view of the CIO and a facility IT manager. Accounting for several project controls, our Cox regression results indicate both integrative dimensions significantly mitigate the duration of IT-related project delays, thus promoting timely project completion. The analysis also reveals the importance of taking management structure into consideration when studying IT phenomena in networked organizations.
\end{abstract}

Index Terms: IT Performance; MIS Management; Knowledge Management; Integrative Capabilities

(C) 2011 Published by MECS Publisher. Selection and/or peer review under responsibility of the Research Association of Modern Education and Computer Science

\section{Introduction}

Estimating completion dates for information technology projects and bringing them in on time is tricky business. IT project is a means of system integration where facilities pass data between multiple legacy and newer systems through a single messaging hub, rather than build custom interfaces to link each system. Companies typically purchase a central module and the specific interfaces they need, then contract for custom programming to build interfaces for proprietary applications. In doing so, they increase the speed of data transfer, reap cost savings, and gain greater flexibility with their business processes. IT project allows users to define business process rules and makes data integration subject to those rules. Thus, the integration of operational rules with technical knowledge is critical to IT project success.

\footnotetext{
* Corresponding author:

E-mail address: cuiyingbaby@126.com
} 


\section{Basics Definitions}

IT project performance embodies two dimensions: product performance and process performance .Product performance refers to the quality of the project outcome or effectiveness of the installed system. In contrast, process performance refers to the quality of the development process - most notably effective planning and efficient implementation. A key indicator of process performance is on-time project completion for a given budget and set of specifications.

Integrative capability refers to an ability to integrate knowledge within and across organizational boundaries. It is analogous to the concept of architectural competence, coined by Henderson and Cockburn (1994) in their study of knowledge transfer in the design of new pharmaceutical products. Both studies demonstrated that research and development project performance was related to an ability to import new external knowledge and synthesize existing internal knowledge. They found higher project performance was associated with knowledge transfer mechanisms that actively encouraged the exchange of information across organizational units and across organizational boundaries. Thus, a proportion of the variance in project performance across firms is attributed to the acquisition and integration of specialized knowledge, particularly when that knowledge is tacit.

\section{Study Design}

\subsection{Measuring the Dependent Variable}

To represent the dependent variable (on-time project completion), the study used the process performance measure time overrun, specifically focusing on IT-related project delays. In pre-implementation phone interviews, respondents provided an estimated completion date for the project. In post implementation phone interviews, respondents provided an actual completion date. When the actual completion date exceeded the target completion date, we queried respondents to identify the primary reason the project was delayed. Where project delays were primarily due to IT-related problems, respondents were asked to elaborate on the underlying reasons these problems occurred and how the situation was resolved.

\subsection{Data Collection}

Data collection took place between 2005 and 2009 as part of a larger research program on the impact of IT in software development services. Although each IT project was followed from startup to completion, this portion of the study focused on knowledge factors affecting timely project completion. The sampling frame consisted of 56 services networks that refer to a multi-organizational conglomerate, typically comprised of 20 or more organizations. IT projects were identified through professional associations, government offices, consulting agencies, and the popular press. We contacted the CEO of each organization, briefly explained the study, and obtained the name of the CIO responsible for integrating applications across networks. CIOs were contacted by telephone, informed of the study, and asked to participate.

\section{Empirical Process}

\subsection{Statistical Methodology}

In a duration analysis that uses Cox regression (one in a family of proportional hazard models), the probability associated with an outcome (called the dependent event) is based on an underlying time variable relative to a set of predictors. Data is collected regarding the dependent event and its time to occurrence, and then a count of the duration time relative to the predictor variables is used to calculate the probability of the 
dependent event occurring. In this study, collecting data on the scheduled and actual completion dates provided an objective measure for the duration of IT delay (our time variable) that was used to calculate the probability of on-time completion for finished projects (our dependent event) for a given set of predictors.

The paper uses Cox regression, a duration analysis approach in which the functional form of the relationship between the predictor variables and the outcome variable need not be specified in order to fit a model to the data. This approach is preferred to other modeling approaches to describe the underlying time dependency of an event when distribution assumptions may not hold. Cox regression is a proportional hazards $(\mathrm{PH})$ regression technique used in survival analysis, event history analysis, reliability analysis, and other types of duration analysis where the out-come variable is time until the occurrence of an event.

\subsection{Model Specification}

Our analysis is based on the following Cox PH model:

$$
h(t, X)=h_{0}(t) \exp \left(\sum_{p} \beta_{i} x_{i}\right)
$$

Where $h(t, X)$ is the hazard rate or likelihood that our event (project completion) will occur at time ${ }^{t}$ given it is not complete at $t-1$ and depends on a set of explanatory covariates $X=\left(x_{1} \ldots x_{p}\right)$.The term $h_{0}(t)$ represents the baseline hazard function, and measures the likelihood of project completion at time ${ }^{t}$ without the explanatory covariates. This baseline hazard function interacts with the expression $\exp \left(\sum \beta_{i} x_{i}\right){ }_{\text {which is }}$ independent of time, to incorporate the effects of the covariates. The term ${ }^{x_{i}}$ denotes an individual covariate, $\beta_{i}$ is the regression coefficient associated with that covariate, and $p$ is the number of covariates in the model. In the context of IT projects, we use this model to understand how our integrative dimensions affect the duration of IT delay impeding project completion, while controlling for project size, user involvement, and project experience.

Table 1. Grambsch and therneau test results for proportionality

\begin{tabular}{cllll}
\hline & & CIO & \multicolumn{2}{c}{ IT Manager } \\
\hline PH Model & $S_{1 \text { controls }}$ & \multicolumn{1}{c}{$S_{1 \text { full }}$} & $S_{2 \text { controls }}$ & $S_{2 \text { full }}$ \\
\hline Global Test $x^{2}$ & 1.16 & 0.74 & 0.18 & 1.24 \\
prob $>x^{2}$ & 0.788 & 0.9871 & 0.9871 & 0.9482 \\
\hline Interfaces rho & 0.003 & -0.033 & 0.028 & 0.023 \\
$x^{2}$ & 0.00 & 0.07 & 0.06 & 0.04 \\
prob $>x^{2}$ & 0.9802 & 0.7986 & 0.8065 & 0.8456 \\
\hline User Involvement & -0.034 & 0.015 & -0.004 & 0.040 \\
& 0.04 & 0.02 & 0.00 & 0.12 \\
Project Experience & 0.8422 & 0.8955 & 0.9735 & 0.7290 \\
& -0.124 & -0.080 & -0.014 & -0.003 \\
Knowledge Integration & 1.04 & 0.46 & 0.02 & 0.00 \\
& 0.3101 & 0.4987 & 0.8973 & 0.9789 \\
\hline
\end{tabular}


The Cox PH model assumes the proportionality of hazards, wherein the relationship between project completion rates and duration of IT-delay remains constant across sets of covariates. Violation of proportionality signals that one or more covariates are time-dependent, and an alternative PH model should be specified. We used the Grambsch and Therneau (1994) tests of the proportional hazards assumption implemented in Stata 8.0 to assess the appropriateness of our model specification. Table 1 shows that the global test chi-square statistic for the Cox models are insignificant, upholding the proportionality assumption.

Next, we tested for a nonzero slope in a generalized linear regression of scaled Schoenfeld residuals on functions of time for each covariate. These test results are also provided in Table 1. The chi-square statistic for each rho is insignificant, indicating all covariates are time-independent in accordance with the proportional hazards assumption.

\subsection{Regression Results}

Table 2. Cox regression results

\begin{tabular}{|c|c|c|c|c|}
\hline \multirow[b]{2}{*}{ PH Model } & \multicolumn{2}{|c|}{ CIO } & \multicolumn{2}{|c|}{ IT Manager } \\
\hline & $S_{1 \text { controls }}$ & $S_{1 \text { full }}$ & $S_{2 \text { controls }}$ & $S_{2 \text { full }}$ \\
\hline \multirow{2}{*}{$\begin{array}{l}\text { Log-Likelihood Ratio } x^{2} \\
\text { Change in LLR } x^{2}\left(G^{2}\right)\end{array}$} & $41.615^{* * *}$ & $48.188^{* * *}$ & $42.688 * * *$ & $48.062 * * *$ \\
\hline & & $5.986 * *$ & & $7.698 * *$ \\
\hline \multirow{4}{*}{$\begin{array}{cc}\text { Interfaces } & \text { z-statistic } \\
& \mathrm{HR}\end{array}$} & $-5.87 * * *$ & $-4.80 * * *$ & $-4.40 * * *$ & $-4.69 * * *$ \\
\hline & 0.57 & 0.604 & 0.62 & 0.588 \\
\hline & -0.584 & -0.507 & -0.488 & -0.530 \\
\hline & $(0.099)$ & $(0.105)$ & $(0.112)$ & $(0.114)$ \\
\hline \multirow{4}{*}{ User Involvement } & $1.96 * *$ & 1.40 & $2.26 * *$ & $2.60 * * *$ \\
\hline & 1.15 & 1.102 & 1.17 & 1.197 \\
\hline & 0.129 & 0.098 & 0.149 & 0.179 \\
\hline & $(0.065)$ & $(0.069)$ & $(0.066)$ & $(0.068)$ \\
\hline \multirow{4}{*}{ Project Experience } & $1.60 *$ & $1.90 * *$ & $1.71 *$ & $1.90 * *$ \\
\hline & 1.28 & 1.358 & 1.49 & 1.572 \\
\hline & 0.245 & 0.307 & 0.392 & 0.453 \\
\hline & $(0.153)$ & $(0.162)$ & $(0.229)$ & $(0.239)$ \\
\hline \multirow{4}{*}{ Knowledge Integration } & & $1.96 * *$ & & $1.84 * *$ \\
\hline & & 1.306 & & 1.228 \\
\hline & & 0.267 & & 0.232 \\
\hline & & $(0.137)$ & & $(0.126)$ \\
\hline
\end{tabular}

Note: Significance levels $* .10, * * .05, * * * .01$

Because Cox regression models are semi-parametric, the traditional $R^{2}$ is not an appropriate measure of model fit. Instead, the log-likelihood ratio $x^{2}$ is used.

Table 2 provides the following Cox regression results: a likelihood ratio chi-square test for goodness of model fit, the change in log-likelihood as the regression model is expanded, the estimated coefficient $(\beta)$, the standard error of the estimated coefficient $\operatorname{SE}(\beta)$, the hazard ratio for a one unit change in the covariate $\exp (\beta)$, and a z-test statistic along with its $\mathrm{p}$-value for the significance of the estimated coefficient. The z-test is sometimes referred to as Wald's test and is calculated as $(\beta / S E)^{2}$.

The paper refers to the z-test statistic in Table 2 to determine which integrative dimensions are most important for predicting on-time project completion. At the corporate level, the CIO's access to knowledge 
integration $(\mathrm{z}=1.96, \mathrm{p}=0.051)$ in model $S_{1 \text { full }}$ indicate both competence dimensions are reliable predictors of on-time project completion. An examination of regression coefficients $(\beta$ ) reveals they have a positive effect on timely project completion.

\section{Conclusion}

The study finds that management's ability to integrate knowledge also increases the probability of on-time completion. As a predictor of on-time project completion, internal knowledge integration is more reliable at the corporate level than at the facility level. we find that, taken together, the integrative dimensions are reliable predictors of project timeliness and good measures of management's integrative capability. we find that two of our three project controls are significant predictors of on-time completion and behave as expected.

\section{Acknowledgements}

This research was supported in part by the founding from the Soft Science Project(102400440010, 2008CSH008)

\section{References}

[1] Altman, R., and Altman, G. “An Integration Primer," Business Integration Journal, February 2004, pp. 57-59.

[2] Argote, L. "Input Uncertainty and Organizational Coordination in Hospital Emergency Units," Administrative Science Quarterly (27), 1982, pp. 420-434.

[3] APM. "Directing Change: A Guide to Governance of Project Management," Association for Project Management, High Wycombe, UK, 2004

[4] Box-Steffensmeier, J., and Jones, B. Event History Modeling: A Guide for Social Scientists, Cambridge University Press, Cambridge, UK, 2004.

[5] Grambsch, P., and Therneau, T. "Proportional Hazards Tests and Diagnostics Based on Weighted Residuals," Biometrica (81:3), 1994, pp. 515-526.

[6] Kleinbaum, D., and Klein, M. Survival Analysis, Springer-Verlag, New York, 1996.

[7] Cleves, M., Gould, W., and Guiterrez, R. An Introduction to Survival Analysis Using Stata, Stata Press, College Station, TX, 2004. 